\title{
PRESENT AND FUTURE POTENTIAL DISTRIBUTION OF THE PINUS NIGRA ARNOLD. AND PINUS SYLVESTRIS L. USING MAXENT MODEL
}

\author{
Arslan, E. Seda ${ }^{1 *}$, Örücü, K. Ömer ${ }^{1}$ \\ ${ }^{I}$ Süleyman Demirel University, Faculty of Architecture, Department of Landscape Architecture, Isparta, Turkey; \\ "Corresponding Author Arslan, E. Seda, email: sedaarslan@sdu.edu.tr;
}

Received September 2019; Accepted October 2019; Published November 2019;

DOI: https://doi.org/10.31407/ijees9425

\begin{abstract}
ASTRACT
Nowadays, modelling habitats by using computer technologies is an effective approach. Analyzing how plant species will be affected by climate change is highly important in terms of defining the habitat areas. With the help of layers formed by using point data for species and digital bioclimate data on these areas, the present and future potential distribution of a species may be determined by the MaxEnt software based on different climate scenarios. This study aimed to model the present and future potential distribution areas of Pinus nigra Arnold. and Pinus slyvestris L., which are significant in terms of landscape architecture and forestry and distributed naturally in Turkey. To determine how the distribution of the species will be affected by climate change, according to the CCSM version 4 (the Community Climate System Model) based on the 5th IPCC report, the species' potential distribution areas in the years 2050 and 2070 were modelled based on RCP 4.5 and RCP 8.5, and the habitat suitability areas were determined digitally. In conclusion, according to the CCSM4 scenario, it is seen that these species will bear substantial losses in their future potential distribution areas.
\end{abstract}

Keywords: MaxEnt, Species distribution model, Pinus nigra Arnold., Pinus slyvestris L. 